\title{
Negishi Cross-Coupling Using Aryl Ethers as Coupling Partners
}

\author{
$\mathrm{Ar}^{2}-\mathrm{ZnMe}_{3} \mathrm{Li}_{2}$ (2.0-3.0 equiv) \\ $\left[\mathrm{NiCl}_{2}\left(\mathrm{PCy}_{3}\right)\right](4 \mathrm{~mol} \%)$ \\ or \\ $\mathrm{Ar}^{1}-\mathrm{OMe}$ \\ $\left[\mathrm{Ni}(\mathrm{cod})_{2}\right](4 \mathrm{~mol} \%) / \mathrm{PCy}_{3}(8 \mathrm{~mol} \%)$ \\ $\mathrm{PhMe}, 25^{\circ} \mathrm{C}$ \\ $\mathrm{Ar}^{1}-\mathrm{Ar}^{2}$ \\ up to $87 \%$ yield
}

$\mathrm{Ar}^{1}=($ substituted $)$ Naph, pyrazyl, pyridyl, 4-CON $(i-\mathrm{Pr})_{2} \mathrm{C}_{6} \mathrm{H}_{4}$

$\mathrm{Ar}^{2}=$ (substituted) $\mathrm{Ph}, p$-/m-anisyl, $p$-/o-/m-Tol, biphenyl, Naph

\section{Selected examples:}<smiles>Cc1cccc(-c2ccc3ccccc3c2)c1</smiles>

$76 \%$ yield

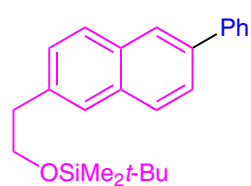

$67 \%$ yield

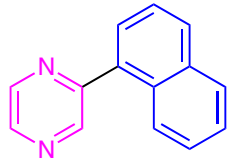

$32 \%$ yield

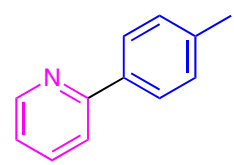

$40 \%$ yield<smiles>CN(C)c1ccc(-c2cccc3ccccc23)cc1</smiles>

$71 \%$ yield<smiles>NC(=NC(=O)c1ccccc1)c1ccc(-c2cccc3ccccc23)cc1</smiles>

$45 \%$ yield
Metal-Mediated

Synthesis

\section{Key words}

zinc

nickel

aryl ethers

C-O activation

cross-coupling

SYNFACThen of the mont
Significance: The first nickel-catalyzed crosscoupling of aryl ethers with aromatic zincates via $\mathrm{C}-\mathrm{O}$ bond cleavage is described. The corresponding biaryls are obtained in moderate to good yields. Electron-rich coupling partners furnish higher product yields than reagents containing electron-withdrawing groups.
Comment: It is noteworthy that, besides the methoxy moiety, this methodology may be extended to ethyl and isopropyl ethers as well. Furthermore, this protocol allows a facile conversion of chiral substrates into the corresponding biaryls without racemization. 